IZA DP No. 8952

Incentives and the Design of Charitable Fundraisers:

Lessons from a Field Experiment

Jeffrey Carpenter

Peter Hans Matthews

March 2015 


\title{
Incentives and the Design of Charitable Fundraisers: Lessons from a Field Experiment
}

\author{
Jeffrey Carpenter \\ Middlebury College \\ and IZA
}

Peter Hans Matthews

Middlebury College

\section{Discussion Paper No. 8952 \\ March 2015}

IZA
P.O. Box 7240
53072 Bonn
Germany

Phone: +49-228-3894-0

Fax: +49-228-3894-180

E-mail: iza@iza.org

\begin{abstract}
Any opinions expressed here are those of the author(s) and not those of IZA. Research published in this series may include views on policy, but the institute itself takes no institutional policy positions. The IZA research network is committed to the IZA Guiding Principles of Research Integrity.

The Institute for the Study of Labor (IZA) in Bonn is a local and virtual international research center and a place of communication between science, politics and business. IZA is an independent nonprofit organization supported by Deutsche Post Foundation. The center is associated with the University of Bonn and offers a stimulating research environment through its international network, workshops and conferences, data service, project support, research visits and doctoral program. IZA engages in (i) original and internationally competitive research in all fields of labor economics, (ii) development of policy concepts, and (iii) dissemination of research results and concepts to the interested public.
\end{abstract}

IZA Discussion Papers often represent preliminary work and are circulated to encourage discussion. Citation of such a paper should account for its provisional character. A revised version may be available directly from the author. 
IZA Discussion Paper No. 8952

March 2015

\section{ABSTRACT \\ Incentives and the Design of Charitable Fundraisers: Lessons from a Field Experiment ${ }^{*}$}

There has been little systematic study of the mechanisms typically used to raise money for charity. One of the most common is the simple raffle in which participants purchase chances to win a prize at a constant price. We conduct a field experiment randomly assigning participants to four raffle treatments to examine the effectiveness of alternative incentive schemes designed to encourage either participation or volume. Our results confirm the importance of incentives in that we find revenue gains are available on both margins. Our experiment, and others like it, illustrates the power of field experiments to inform fundraising choices.

JEL Classification: H41, D03, D64, C93

Keywords: philanthropy, fundraising, incentives, public good, raffle, Tullock contest, field experiment

Corresponding author:

Jeffrey Carpenter

Department of Economics

Middlebury College

Middlebury, VT 05753

USA

E-mail: jpc@middlebury.edu

\footnotetext{
* We thank Corinna Noelke and Carolyn Craven for helpful discussion, as well as Tyler Callese, Audrey Carpenter, Henry Carpenter, Philip Chang, Tawanda Chipwanya, Jenner Currier, Peter Ekelmans, Matthew Forsberg, Martha Gilchrist, Lisa Han, Stewart Hoffman, Douglas Kenerson, Rachel Kim, Jane McCabe, William Moore, Liam Mulhern, Katherine Neal, Dorrie Paradies, William Potter, Ethan Roy, and Arjun Shah for research assistance. We also acknowledge the financial support of Middlebury College and the National Science Foundation (SES 0617778).
} 


\section{Introduction}

Most readers will be familiar with the (almost certainly apocryphal) story of Emperor Nero, singing and playing his lyre during the Great Fire of Rome in 64 ACE. Fewer will know, however, that drawing on the successful practices of Nero, Augustus and others as overseers of Roman public finance, the empire relied on lotteries to rebuild after the fire (Baker 1958). And with more than a millennium and a half before the first government bond issue - most, if not all, economic historians would identify the Bank of England's sale of a tontine in 1693 the first such example - the lottery remained, and in some economies still remains, an important fundraising mechanism. Over the same long period, local institutions and even individuals adopted their own variants of the mechanism to raise funds, the most important of which was the raffle.

When in 1446, the widow of the great Flemish painter Jan van Eyck wanted to liquidate a number of his paintings, she turned not to thin or non-existent art markets but to raffles, one of the earliest recorded examples of the practice (Sweeney 2009). Since then, charities and other non-profits have counted on this mechanism to convert illiquid gifts and other assets into cash. The economic logic of raffles differs somewhat from that of lotteries, in which the prizes are cash, often a share of the proceeds themselves, and in which the relevant planning decision is whether to sell tickets or solicit more direct contributions to some public good (Duncan 2002). The surprise, perhaps, is that both the theoretical and empirical literatures on raffles, as opposed to lotteries, are so thin. The experiment closest to ours is a lab study, Dale (2004), which tests how designing lotteries (and raffles) with fixed cash prizes (or goods of fixed value) affects the amount of money raised compared to revenue-dependent or "parimutuel" lotteries where the prize depends on how much money is raised (e.g., the familiar 5050 lottery). Because fixed prize lotteries better align public and private incentives (Morgan, 2000) they are expected to raise more money, a prediction confirmed by the experimental data.

In the field, Landry et al. (2006) conduct a fundraising experiment door-to-door in which participants are randomized into four treatments. In two treatments, the solicitors asked for voluntary contributions to a research center at the local university. What differentiated these two treatments was that seed money had been donated in one and not in the other. In the other two treatments fixed prize lotteries were used. Participants in the third treatment contributed to the charity by buying lot- 
tery tickets for a single $\$ 1000$ prize. In the fourth treatment there were four $\$ 250$ prizes. As predicted (again based on the seminal work of Morgan, 2000), the lotteries yielded significantly more donations than the voluntary contribution treatments. Comparing between lotteries, the large single prize attracted both more participants and higher per-participant contributions. Also in the field, Onderstal et al (2013) compare voluntary contributions to a raffle (and an all-pay auction), again in the context of door-to-door fundraising, this time in the Netherlands. Their data does not show a clear advantage of the raffle over voluntary contributions and the authors speculate that offering a prize to raise money might crowd out the intrinsic motivation to give. As important as the contributions of these papers are, we are aware of no other studies that consider the question posed here, namely, can simple rule/incentive changes in the way chances of winning are allocated, for example - improve revenue from the raffle?

The answer is important to both academics and practitioners for several reasons, not least of which are the enormous annual flows of donated goods and services. In 2008, for example, 40 million of the itemized personal tax returns filed in the United States claimed deductions for charitable donations and more than half of these returns (23 million) listed donations in-kind. Since the start of the recent recession, people have continued to give and the data suggest that they have shifted even further towards making non-cash donations as budgets tightened. In fact, one estimate suggests that while overall charitable donations fell by $3.2 \%$ in 2009 , the fall would have been much more dramatic had it not been for in-kind contributions, which increased almost $30 \%$ (Giving USA, 2010).

Because the staff members of charities and non-profits are often more adept at soliciting gifts than transforming them into cash - a reflection, perhaps, of broader uncertainties about "best practice" - the flow of in-kind contributions creates ongoing challenges. While auctions are a common recourse, the workhorse of the small scale charitable fundraiser is clearly the raffle. Its appeal owes much to the fact that it seems fair to (most) participants and is simple to implement, especially in situations in which participants cannot all gather at the same time. It is unclear, however, whether the standard raffle format is optimal, that is, whether some more efficient variation on this mechanism might serve charities and non-profits better.

In the standard raffle, chances of winning the prize (i.e., tickets) are sold at a fixed price and one's total expenditure is a simple linear function of the number of tickets 
purchased. There is no reason to believe, however, that the standard linear scheme is optimal. The research question here is whether one can improve the raffle by manipulating the incentives at both the extensive and intensive margins of the mechanism. On the extensive margin, we ask whether the allocation of winning chances can be redesigned to encourage participation and, if so, what the consequences for revenue might be. On the intensive margin, we ask whether the allocation mechanism can be redesigned to encourage donors to purchase more tickets, conditional on participation.

There is some reason to believe that a redesigned raffle could indeed raise more money. For example, it is sometimes said that raffles are inefficient "all-pay auctions" because the participant who spends or "bids" the most is not a certain winner, just the most probable one. If participants with high valuations of the donated good who purchased more tickets expected more than proportional increases in the likelihood of winning, they might spend more on tickets. In other words, a convex raffle in which the marginal number of tickets received increases as one spends more might extend the mechanism's intensive margin - conditional on participating at all, people might decide to purchase more tickets.

On the extensive margin, one reason that people seem to like to participate in raffles is the perception that everyone, even someone who purchases a single ticket, has a chance to win. This is broadly consistent Clotfelter and Cook's (1990) "chance to buy hope" hypothesis, and with some anecdotal evidence reported in Carpenter, Holmes and Matthews (2008). With this in mind, one could instead construct a concave raffle, in which the marginal number of tickets received actually decreases as participants spend more. Potential donors who are equity-minded, for example, might be more willing to participate because "anyone can win," especially in cases where the marginal cost of tickets rises very sharply after the first few.

It is worth underscoring, however, that these incentives work in opposite directions. In the concave raffle, more potential donors will participate but each will purchase a small(er) number of tickets, while in the convex raffle, fewer participants should each purchase more tickets. From a common reference point, say the expenditure of $\$ 5$ for five tickets in each format, in the convex raffle participants should purchase more tickets partially because they find it easier to overcome the externality emitted from additional purchases by other participants. Here the marginal cost of another ticket falls and so if one's competitor buys another ticket reducing one's chances to win it is less costly to nullify this externality. This is different in the concave raffle, however. 
Here, because the marginal cost of another ticket is increasing, if your competitor buys another ticket, it is increasingly costly to recover.

In the end, the question as to which margin matters more for raffle organizers is an empirical one. That is, do non-profits earn more from a larger number of modest ticket purchases or from a smaller number of large purchases? In the spirit of Mason's (2013) recent case for using field experiments to "put charity to the test," we conducted an experimental evaluation of the effects of convex and concave schemes on raffle revenues. We sold raffle tickets door-to-door in Addison County, Vermont to benefit a local charity and randomly assigned households to one of four treatments: a standard linear raffle in which the marginal number of tickets remained constant as one's expenditure increased, a convex raffle in which the marginal number of tickets received increased, and two concave raffles in which the marginal number of additional tickets fell as one spent more. The two concave raffles differ in the severity of their incentives. In what we call the concave raffle, the marginal number of tickets falls gradually as one increases one's expenditure (a natural opposite of the convex raffle) and in what we call the "pay what you want" raffle every participant who contributes the minimum receives the same fixed number of tickets but (like Gneezy et al., 2010) is free to contribute whatever they like above the minimum. Here the incentives are sharp and fairness is particularly salient: every participant is allocated exactly the same number of tickets and there is no way to increase your chances of winning by spending more.

Our results suggest there is a substantial opportunity cost associated with the linear raffle used so commonly. We find that, as theory suggests, revenue improvements can be had on both margins. Making the raffle more convex does increase donations, conditional on participation and making it concave incents participation, thought the participation result is sensitive to the formulation of the concavity. The concave raffle does not perform well, we suspect because the implied quantity "penalty" is unintuitive but the more extreme, pay what you want, version which puts fairness front and center does elicit considerably more donors than any other format. In the end, the average donation per solicitation is greater in both the convex raffle and the pay what you want raffle compared to the linear benchmark, offering two paths to improved raffle performance and demonstrating the power of properly developed incentives to impact the economics of philanthropy. 


\section{Charitable raffle design}

We first describe a simple model that provides the intuition for the raffle modifications we propose. Based on the standard formulation of Morgan (2000), suppose there are $N$ potential (risk neutral) donors indexed $i=1 \ldots N$, each of whom has an endowment, $w_{i}$, to spend on raffle tickets. Active donors spend $x_{i}$ for chances to win a prize, $R$. Lastly, we allow donors to feel some "warm glow" towards the charity, $0<\alpha<\frac{1}{N}$, but not so much that altruism swamps strategic concerns. Altogether, the utility faced by each potential raffle contributor is:

$$
U_{i}=\left(w_{i}-x_{i}\right)+\left(\frac{x_{i}^{\beta}}{\sum x_{i}^{\beta}}\right) R+\alpha\left(\sum x_{i}-R\right) .
$$

The small innovation here, adopted to suit our purposes, is that we utilize the generalized contest success function, $x_{i}^{\beta} / \sum x_{i}^{\beta}$, offered by Tullock (1980). As one can easily see, the standard, linear, raffle is just the special case where $\beta=1$. However, when $\beta>1$, chances of winning accrue faster to donors who spend more (our convex raffle) and when $\beta<1$, they accrue more slowly (our concave raffle). In other words, the raffle becomes closer to its efficient cousin, the all-pay auction, as $\beta$ rises past one and it more closely resembles the completely fair, pay what you want, mechanism in which the prize is allocated randomly to one of the donors as $\beta \rightarrow 0$.

To examine the intensive margin, donors maximize $U_{i}$ by correctly choosing $x_{i}$. The first order condition, after a bit of simplification, is just:

$$
R\left[\frac{\left(\sum_{\sim i} x_{j}^{\beta}\right) \beta x_{i}^{\beta}}{\left(\sum x_{i}^{\beta}\right)^{2}}\right]=1-\alpha
$$

and allowing $x_{i}=x_{j}=x$ at the symmetric equilibrium, we find:

$$
x^{*}=\frac{\beta(N-1) R}{N^{2}(1-\alpha)},
$$

an increasing function of $\beta$. This confirms our intuition that, on the intensive margin, we should expect participants to increase their donations to charity as raffles become more efficient - more "convex."

Considering the extensive margin, we follow a standard method for analyzing endogenous entry into contests based on Cocoran (1984), one that has been used more recently in Morgan et al., (2012). Specifically, we exploit the fact that in any pure strategy equilibrium, the number of participants is determined by the marginal entrant who drives the expected benefit from participating below an outside option, say $\underline{U}$. 
Evaluated at $x^{*}$, the expected utility of participants is, after some simplification,

$$
w_{i}+R\left(\frac{1}{N}-\alpha\right)\left[1-\frac{\beta(N-1)}{N(1-\alpha)}\right]
$$

which is decreasing in $N$ as long as there is not too much warm glow (i.e., $\frac{1}{N}>\alpha$ ) and equal to $\underline{U}$ for the marginal donor. For simplicity, suppose that $\underline{U}$ is just equal to the wealth endowment, $w_{i}$, in which case we can solve the following for $N^{*}$.

$$
R\left(\frac{1}{N}-\alpha\right)\left[1-\frac{\beta(N-1)}{N(1-\alpha)}\right]=0
$$

It is reasonable to assume that neither $R$ nor $\left(\frac{1}{N}-\alpha\right)$ are equal to zero which leaves the last term from which we can calculate the equilibrium number of donors,

$$
N^{*}=\frac{\beta}{\beta+\alpha-1},
$$

a number that decreases with $\beta$ and is defined as long as $\beta+\alpha>1$. As one can see, for reasonable parameter values, our intuition about the extensive margin is also correct. Making the raffle more convex should enhance donations, but it will likely come at the expense of participation. If charities are primarily interested in building a warm list of donors, they might actually consider using a concave raffle.

\section{Methods}

Randomized field experiments have recently revolutionized the way that empirical work has been conducted both in economics generally (Angrist and Pischke, 2009) and, more specifically, in the economics of charity (List, 2008). The real benefit of this methodology is that one can confidently estimate causal effects with modest samples. If participants are randomized to treatment any observed or unobserved traits should be balanced and their effects will therefore be orthogonal to the estimated treatment effects.

To implement the treatments of our experiment, we first decided on five "donation levels" that would be the common link between treatments along with a $\$ 500$ prize. We picked round amounts that would be prominent and facilitate making change in the field. Participants could donate $\$ 5, \$ 10, \$ 20, \$ 40$ or $\$ 60$. In accordance with the Tullock structure used in Section 2, what changed from treatment to treatment was 
the number of raffle tickets that the participant received for each donation. The details of our treatments are illustrated in Table $1 .^{1}$

\begin{tabular}{c|ccc|ccc|ccc|ccc}
\hline & \multicolumn{3}{|c|}{ Convex } & \multicolumn{3}{|c|}{ Linear } & \multicolumn{3}{c|}{ Concave } & \multicolumn{3}{c}{ PWYW } \\
Donation & $\mathrm{T}$ & $\mathrm{C} / \mathrm{T}$ & $\mathrm{MC}$ & $\mathrm{T}$ & $\mathrm{C} / \mathrm{T}$ & $\mathrm{MC}$ & $\mathrm{T}$ & $\mathrm{C} / \mathrm{T}$ & $\mathrm{MC}$ & $\mathrm{T}$ & $\mathrm{C} / \mathrm{T}$ & $\mathrm{MC}$ \\
\hline$\$ 5$ & 5 & $\$ 1.00$ & 1.00 & 5 & $\$ 1.00$ & 1.00 & 5 & $\$ 1.00$ & 1.00 & 5 & $\$ 1.00$ & 1.00 \\
$\$ 10$ & 13 & $\$ 0.77$ & 0.63 & 10 & $\$ 1.00$ & 1.00 & 9 & $\$ 1.11$ & 1.25 & 5 & $\$ 2.00$ & - \\
$\$ 20$ & 30 & $\$ 0.67$ & 0.59 & 20 & $\$ 1.00$ & 1.00 & 15 & $\$ 1.33$ & 1.67 & 5 & $\$ 4.00$ & - \\
$\$ 40$ & 70 & $\$ 0.57$ & 0.50 & 40 & $\$ 1.00$ & 1.00 & 25 & $\$ 1.60$ & 2.00 & 5 & $\$ 8.00$ & - \\
$\$ 60$ & 120 & $\$ 0.50$ & 0.40 & 60 & $\$ 1.00$ & 1.00 & 30 & $\$ 2.00$ & 4.00 & 5 & $\$ 12.00$ & - \\
\hline
\end{tabular}

Note: $\mathrm{T}$ is tickets received, $\mathrm{C} / \mathrm{T}$ is cost per ticket, and $\mathrm{MC}$ is marginal cost.

\section{Table 1: Raffle treatment parameters.}

Our linear raffle was designed to be straightforward and representative of what is typically utilized by charitable organizations. For a $\$ 5$ donation, participants were given 5 tickets, they received 10 tickets for $\$ 10,20$ tickets for $\$ 20$, and so on such that the marginal (and average) cost was constant and set at $\$ 1$.

By comparison, the convex treatment was designed to enhance the efficiency of the raffle and incent larger donations by disproportionately awarding chances of winning to those participants who donated more. We simply implemented the convex raffle as a quantity discount with decreasing marginal (and average) cost. Here the cost per ticket fell from $\$ 1$ to $\$ 0.50$ as the participant purchased more. In other words, 5 raffle tickets were given for a $\$ 5$ donation, 13 were given for $\$ 10,30$ for $\$ 20$ and 70 were given for $\$ 40$. For a $\$ 60$ donation convex participants were given 120 tickets, twice the number received by their linear counterparts.

Because the concave raffle was supposed to encourage a sense that "anyone can win" and therefore participation, we imposed a quantity penalty that increased in severity. In this case, the cost per ticket increased with the expenditure from $\$ 1$ to $\$ 2$. The concave raffle started with 5 tickets for $\$ 5$ but only rewarded 9 tickets for a $\$ 10$ donation, only 15 for $\$ 20,25$ for $\$ 40$ and just 30 for $\$ 60$, half the number given in the linear treatment.

\footnotetext{
${ }^{1}$ The ticket numbers for the convex and concave treatments correspond, roughly, to Tullock values $(\beta)$ of 1.15 and 0.85 , values that generate the predictions of Section 2 for properly specified participation thresholds.
} 
Our pay what you want raffle (PWYW) is novel for a number of reasons. The PWYW raffle is an extreme version of the concave raffle in that all participants received the same number of tickets, regardless of their donations (i.e., the Tullock $\beta=0$ ). In other words, participants could not affect their chances of winning the prize by donating more. As a result, all participants had exactly the same chance of winning the prize which makes the mechanism "fair." This fairness should enhance participation, both in theory and in practice. Notice also that any donation above the $\$ 5$ minimum, must have been voluntary because donating more did not increase one's odds of winning the prize. This observation makes the PWYW treatment a nice benchmark comparison to the literature on voluntary contributions (e.g., Landry et al., 2006 or DellaVigna et al., 2012). ${ }^{2}$ In fact, the PWYW treatment allows us to cleanly ask whether the incentives to donate more to increase ones chances of winning a prize crowd in (or crowd out) voluntary contributions. If we see a lower frequency of donations above the minimum in the PWYW raffle, it must be because strategic incentives crowd in donations. However, if the frequency of non-minimum donations is larger in the PWYW, strategic incentives must crowd out altruism (as discussed in Bowles and Polania-Reyes, 2012).

It is important to note that one could buy 5 tickets for $\$ 5$ in all four raffles and we told our participants that our goal was to get 100 donations (per treatment). Not only was this done to manage the expectations of the participants about how many tickets might be sold (and that at best they could expect to break even on a $\$ 5$ donation), we did it to equalize the incentives surrounding an expenditure of $\$ 5$, identified in the broader literature as a useful benchmark. In their experiment on door-to-door fundraising, for example, Landry et al. (2006) compared lotteries with single and multiple cash prizes to simple voluntary contributions and found that in the single prize lottery, the average contribution, conditional on participation, was $\$ 4.39$. We standardized incentives at this level so that improvements (or otherwise) could be defined relative to the representative experience of fundraisers.

To describe the exact protocol in more detail, the prize for each of the raffles was a $\$ 500$ gift certificate that was redeemable at five unique local restaurants, all managed

\footnotetext{
${ }^{2}$ In fact, one could argue that previous comparisons of raffles and voluntary contributions are problematic in that two things change - in raffles and lotteries there is a prize which is not present when eliciting voluntary contributions and raffle participants can affect their chances of winning the prize, a different strategic element. In our implementation all formats offer a prize so only strategic concerns differ between treatments.
} 
by the same holding company. ${ }^{3}$ To promote the fundraiser, we ran weekly full- or halfpage advertisements in the local newspaper and hung posters around the data collection area at local gathering places (e.g., grocery stores and shop windows). As an act of beneficence, the restaurant holding company donated three-quarters of the total prize value (i.e., $\$ 1500$ of the $\$ 2000$ ) which also helped extend the external validity of the study by allowing us to list the holding company as the donor in all the advertisements.

All the proceeds from the raffles went to a well-known local poverty relief organization started in 1965 to complement the Johnson administration's "war on poverty." The organization's mission is to provide food assistance (via a food bank) and other basic needs (such as heating fuel assistance), job training and counseling to individuals and families in the surrounding county. The organization receives donations via the local chapter of the United Way and runs a number of fundraisers each year, making our raffle seem as part of "standard practice" to the local community.

Throughout the month of April 2014, our research assistants, in teams of two, visited approximately 1750 homes in Addison County, Vermont and during 849 of these visits, someone answered the door. Given the population density in western Vermont, 849 observations represents a significant sample. ${ }^{4}$ All visits took place on weekdays during the early evening. Prior to knocking on the door, the research assistants randomized each home into one of the four raffles by drawing colored chips from an opaque bag. If the door was opened, the research assistants followed a standardized script (which appears as an appendix) that varied only in the description of the number of tickets that would be awarded for each donation. For each treatment a laminated table was used to illustrate the mapping from donation levels to tickets purchased. The assistants accepted cash or checks made out directly to the beneficiary. Following the exchange, the research assistants recorded whether or not a donation had been made, the number of tickets purchased and their identification numbers (for the subsequent drawing of the prize winners). Once off the stoop, they also recorded the home's address and the gender and estimated the age of the person who made the donation decision.

After all the raffle data was consolidated from the field, we made use of administrative records from the poverty relief organization and the local town clerks to add information on whether the households had previously given directly to the organization and the assessed values of the homes we visited. We collected data on previous

\footnotetext{
${ }^{3}$ The protocol for our experiment was reviewed and approved by the Middlebury College IRB.

${ }^{4}$ According to the census, in 2010 Addison County had 36,820 residents and 14,141 households.
} 
donations to account for "warm list" affects (à la Landry et al., 2010) and the home assessments were gathered to provide a proxy for wealth as a correlate of the demand for charitable giving.

\section{Results}

Considering all the home visits conducted by our solicitor teams, the door was answered by someone approximately half the time, resulting in 849 donation decisions being observed. During 434 of these visits (51\%) the respondent made a donation. These 434 purchases were distributed in such a way that we achieved our stated target of gathering roughly 100 donations per raffle. These donations also assured that our fundraiser was very successful - in total we raised $\$ 4263$ using $\$ 2000$ worth of donated prizes. Compared to a benchmark in this literature our fundraising results were similar, if not a bit more successful. Our response and purchase rates are slightly better than, but in the same ballpark as, those Landy et al. (2006) obtained for their single prize lottery (38\% and $45 \%$, respectively). However, the mean expenditure, conditional on participation, in our sample was considerably larger: $\$ 9.82$ versus $\$ 4.39$. We are comfortable, then, with our protocol, even as we acknowledge the benefits of our location and identification with our local beneficiary.

\begin{tabular}{ccccc}
\hline & Linear & Convex & Concave & PWYW \\
\hline Female $(\mathrm{I})$ & $0.57(0.50)$ & $0.53(0.50)$ & $0.60(0.49)$ & $0.60(0.49)$ \\
Estimated Age & $50.51(14.88)$ & $51.05(14.71)$ & $50.71(15.93)$ & $51.13(14.17)$ \\
Previous Donor $(\mathrm{I})$ & $0.17(0.38)$ & $0.17(0.38)$ & $0.17(0.38)$ & $0.17(0.37)$ \\
Home Value $(\div 100 k)$ & $2.51(1.59)$ & $2.44(1.47)$ & $2.49(1.47)$ & $2.42(1.57)$ \\
\hline
\end{tabular}

Note: means and (standard deviations).

Table 2: Treatment balance on observables.

Table 2 presents summary data on the characteristics of the homes we visited and the people who answered the door, by treatment. Overall, $57 \%$ of the people who answered the door were female, the average estimated age of these people was 51 years, and $17 \%$ had previously given to the beneficiary (i.e., they were on the warm list). Given the similarities in the disaggregated data, we seem to have achieved random assignment to treatment. Using t-tests to check, the lowest observed p-value, 0.13, 
comes from the comparison of the frequency of female respondents in the convex and PWYW raffles.

We now proceed by examining the differences that arise between treatments. We begin by examining the extensive margin - to what extent are people more (or less) likely to donate in the four treatments? We then examine the intensive margin conditional on giving, do people give more in some mechanisms than in others? Finally, we consider the combined effects of participation and giving by looking at the difference that matters most to charities, the one in mean donations, including any zeros.

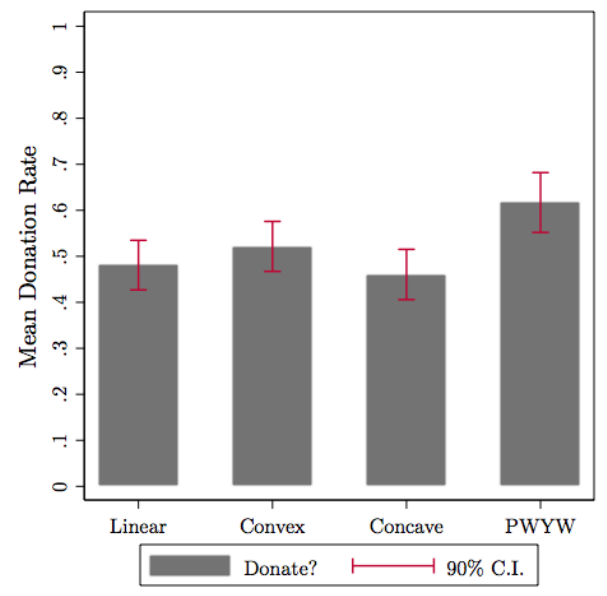

Figure 1: Extensive margin (by treatment).

We evaluate performance on the extensive margin by comparing participation rates across our four treatments. These rates are summarized in Figure 1 which illustrates the mean rate of donation, by treatment, for the 849 cases in which the door was opened. As one can see, the participation rates hover around $50 \%$, the overall rate of giving. For example, in the linear, benchmark, format $48 \%$ of respondents donated. By comparison, the convex raffle yielded slightly greater participation (52\%), though not significantly more $(p=0.38)$. The concave raffle which was expected to enhance participation actually yielded fewer donations (46\%), but, again, the difference is not significant in the raw data $(p=0.66)$. The more extreme version of the concave raffle, the PWYW, however, does appear to elicit more donations. Here the $62 \%$ participation rate is significantly greater than the linear point of reference $(p<0.01) .^{5}$

\footnotetext{
${ }^{5}$ The PWYW raffle also yields significantly higher participation than the concave $(p<0.01)$ and convex $(p=0.06)$ raffles. None of the other differences are significant in the raw data.
} 
For a more rigorous evaluation of participation, consider the regression results reported in Table 3. Here the dependent variable is one when a donation is made and zero otherwise. The omitted format, is the Linear benchmark. To make the point estimates easier to interpret we report linear probability results and robust standard errors. Column (1) of Table 3 simply reproduces our summary results: the linear raffle yields donations $48 \%$ of the time, contrary to theory the convex does about 4 percentage points better (n.s.) and the concave does about 2 percentage points worse (n.s.), while the PWYW Raffle is consistent with theory, boasting a participation rate almost 14 percentage points greater than the linear $(p<0.01)$.

\begin{tabular}{lcccc}
\hline & $(1)$ & $(2)$ & $(3)$ & $(4)$ \\
\hline Convex - Qty. Discount (I) & 0.041 & 0.044 & 0.045 & 0.047 \\
& $(0.046)$ & $(0.046)$ & $(0.045)$ & $(0.045)$ \\
Concave - Qty. Penalty (I) & -0.020 & -0.021 & -0.020 & -0.019 \\
& $(0.046)$ & $(0.047)$ & $(0.046)$ & $(0.046)$ \\
Pay What You Want (I) & $0.136^{* * *}$ & $0.134^{* * *}$ & $0.135^{* * *}$ & $0.138^{* * *}$ \\
& $(0.051)$ & $(0.051)$ & $(0.051)$ & $(0.051)$ \\
Female (I) & & $0.078^{* *}$ & $0.078^{* *}$ & $0.077^{* *}$ \\
& & $(0.035)$ & $(0.034)$ & $(0.034)$ \\
Estimated Age $<30$ (I) & & -0.018 & 0.010 & -0.000 \\
Estimated Age $>60$ (I) & & $(0.075)$ & $(0.077)$ & $(0.078)$ \\
& & -0.058 & $-0.068^{*}$ & $-0.073^{*}$ \\
Previous Donor (I) & & $(0.040)$ & $(0.040)$ & $(0.039)$ \\
& & & $0.215^{* * *}$ & $0.196^{* * *}$ \\
Home Value (hundred thousands) & & & $(0.043)$ & $(0.044)$ \\
& & & & $0.031^{* *}$ \\
Constant & & & & $(0.014)$ \\
& 0.012 & 0.020 & 0.046 & 0.055 \\
\hline
\end{tabular}

Note: Dependent variable is whether one donates or not; linear probability with robust (standard errors); * $\mathrm{p}<0.10, * * \mathrm{p}<0.05, * * * \mathrm{p}<0.01$.

Table 3: Examining differences on the extensive margin. 
In the second column of Table 3, we add the responder attributes collected on the doorstep. Given the balance seen in Table 2, it comes as no surprise that the addition of these attributes has little effect on the treatment point estimates. That said, we do find that women are more likely to donate, almost $8 \%$ more $(p=0.03)$, and that respondents estimated to be less than 30 years old or older than 60 do donate less often, but not significantly so. In columns (3) and (4) we add our adminstrative data and confirm a number of important results reported in the related literature. Respondents on the warm list are approximately $20 \%$ more likely to give again and a hundred thousand dollar increase in the value of one's home is associated with being 3 percentage points more likely to give. As a robustness check, Table A1 in the appendix replicates these results using regressions that include solicitor team fixed effects. ${ }^{6}$

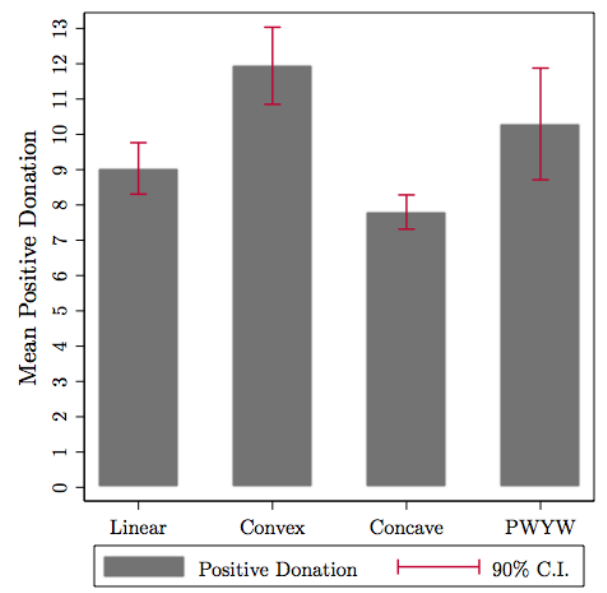

Figure 2: Intensive margin (by treatment).

Switching focus to the intensive margin, in Figure 2 we present the mean positive donations for each raffle treatment. That is, conditional on participating, how much, on average, do people donate? As before, we begin with the linear reference treatment. Here we see that our participants are quite generous, donating an average of $\$ 9.03$. Despite this munificence, the quantity discount does seem to motivate convex raffle participants as predicted. The average donation in this mechanism is $\$ 11.94$ which is significantly greater than the benchmark $(p=0.01)$. As also predicted, donation amounts do fall in the concave raffle which yields the lowest mean gift of $\$ 7.80$, though

\footnotetext{
${ }^{6}$ We also considered clustering the standard errors by solicitor team but there simply were not enough teams to make doing so efficient.
} 
the decrement from the Linear Raffle only verges on significance using a t-test ( $p=$ 0.11). Given it is an extreme version of the concave, we are surprised to see that the PWYW raffle actually gave rise to an average donation of $\$ 10.29$ though, again, this is not significantly greater than what was gathered by the linear raffle $(p=0.34) .^{7}$

\begin{tabular}{lcccc}
\hline & $(1)$ & $(2)$ & $(3)$ & $(4)$ \\
\hline Convex - Qty. Discount (I) & $2.907^{* * *}$ & $2.874^{* * *}$ & $2.655^{* *}$ & $2.633^{* *}$ \\
& $(1.115)$ & $(1.121)$ & $(1.062)$ & $(1.056)$ \\
Concave - Qty. Penalty (I) & -1.235 & -1.212 & $-1.323^{*}$ & $-1.355^{*}$ \\
& $(0.769)$ & $(0.782)$ & $(0.748)$ & $(0.744)$ \\
Pay What You Want (I) & 1.259 & 1.253 & 1.541 & 1.718 \\
& $(1.372)$ & $(1.374)$ & $(1.374)$ & $(1.376)$ \\
Female (I) & & -0.376 & -0.157 & -0.196 \\
& & $(0.982)$ & $(0.934)$ & $(0.926)$ \\
Estimated Age $<30$ (I) & & -0.342 & 1.049 & 1.065 \\
Estimated Age $>60$ (I) & & $(2.120)$ & $(2.087)$ & $(2.141)$ \\
& & -0.472 & -0.573 & -0.814 \\
Previous Donor (I) & & $(0.826)$ & $(0.811)$ & $(0.798)$ \\
& & & $5.523^{* * *}$ & $5.277^{* * *}$ \\
Home Value (hundred thousands) & & & $(1.376)$ & $(1.365)$ \\
& & & & $0.830^{* * *}$ \\
Constant & & & & $(0.281)$ \\
& & & & \\
Observations & 0.032 & 0.033 & 0.100 & 0.117 \\
\hline
\end{tabular}

Note: Dependent variable is donation, conditional on being positive; OLS with robust (standard errors); ${ }^{*} \mathrm{p}<0.10,{ }^{* *} \mathrm{p}<0.05,{ }^{* * *} \mathrm{p}<0.01$.

Table 4: Examining differences on the intensive margin.

In Table 4 we expand our analysis of donations. The first column of Table 4 confirms that the convex raffle yields an average of $\$ 2.91$ per participant more than the Linear

\footnotetext{
${ }^{7}$ As for the other treatment comparisons, the convex raffle yields greater average donations than the concave $(p<0.01)$ as does the PWYW $(p=0.05)$, but positive donations in the convex and PWYW Raffles are statistically indistinguishable $(p=0.27)$.
} 
Raffle and that this increment is highly significant. As in the simpler analysis, neither the mean positive donation in the concave format nor the one in the PWYW differs significantly from the linear format. While the responder observables again have little effect on the raffle treatment point estimates, they also add little to the analysis of the intensive margin in column (2). Conditional on giving, female respondents seem to donate about as much as males and, as was the case with participation, the young and old appear to give a bit less than those in middle age but here the differences are never significant. Again, however, we do see strong effects from our administrative data in columns (3) and (4). Previous donors tend to give more than five dollars more than new donors $(p<0.01)$ and donors give $\$ 0.83$ more for each hundred thousand dollar increase in the value of their homes $(p<0.01)$. Again, adding solicitor team fixed effects changes these results very little. These robustness checks can also be examined in the appendix (Table A2).

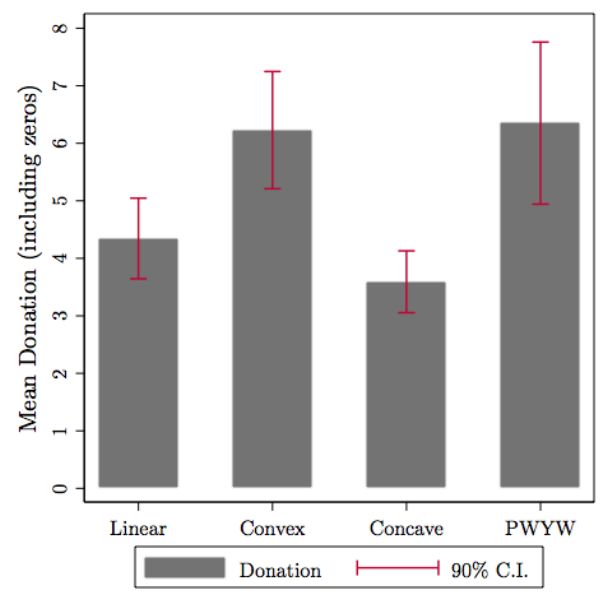

Figure 3: Combined effects on donations (by treatment).

So far the data indicate that charities wanting to expand participation should focus on formats that stress fairness while those trying to squeeze larger donations out of a fixed group of donors might consider emphasizing efficiency. When all is said and done, however, charities are most concerned about the total amount raised (or the amount raised per solicitation), the combined effects of participation and giving. To assess "the bottom line" result of our field experiment we now consider all the donation data, including the zeros. 
In Figure 3 we present the mean donation for each raffle format, including zeros for all the instances in which a respondent answered the door but did not donate. Starting with the formats that performed less well, in the baseline, linear, format the mean donation is $\$ 4.34$, an amount that is 75 cents larger than the poorest performing format, the concave treatment, but the difference is not quite significant $(p=0.16)$. Both the concave and Linear raffles perform less well overall than either of the other two formats. Apparently both "paths" to a greater than typical amount raised are viable. In the convex raffle where efficiency is emphasized the mean contribution raised per solicitation is $\$ 6.23$, an amount significantly greater than both the linear and concave raffles ( $p \leq 0.01$ in both cases). As an alternative, in the PWYW format which stresses the fact that every participant has the same "fair" chance of winning, the mean gift is $\$ 6.35$, again an amount significantly greater than both the linear and concave formats $(p \leq 0.02$ for both). Interestingly, we see no clear best way to run a raffle - the mean contributions in the convex and PWYW do not differ significantly $(p=0.91)$.

We conclude our presentation of the results with a discussion of Table 5 which presents an ordinary least squares analysis based on the entire sample of donations. Column (1) indicates, again, that both the efficiency-focussed convex raffle and the fairness-focussed PWYW raffle do significantly better than the standard linear raffle. At the same time, a comparison of the convex and PWYW point estimates confirms that they do equally well compared to the linear raffle $(p=0.91)$. Considering the other possible determinants of contributions in columns (2)-(4), we see an effect of being older than middle-aged - older respondents give less - but the result is not robust. What continues to be robust, however, is that previous donors give approximately twice as much and wealthier respondents, as measured by the assessed value of their homes, also give more $(p<0.01$ for both). 


\begin{tabular}{|c|c|c|c|c|}
\hline & (1) & $(2)$ & (3) & (4) \\
\hline \multirow[t]{2}{*}{ Convex - Qty. Discount (I) } & $1.884^{* *}$ & $1.909^{* *}$ & $1.929^{* * *}$ & $1.966^{* * *}$ \\
\hline & $(0.749)$ & $(0.750)$ & $(0.712)$ & $(0.708)$ \\
\hline \multirow[t]{2}{*}{ Concave - Qty. Penalty (I) } & -0.753 & -0.742 & -0.715 & -0.700 \\
\hline & $(0.535)$ & $(0.539)$ & $(0.521)$ & $(0.519)$ \\
\hline \multirow[t]{2}{*}{ Pay What You Want (I) } & $2.006^{* *}$ & $1.986^{* *}$ & $2.028^{* *}$ & $2.077^{* *}$ \\
\hline & $(0.951)$ & $(0.960)$ & $(0.951)$ & $(0.950)$ \\
\hline \multirow[t]{2}{*}{ Female (I) } & & 0.596 & 0.599 & 0.587 \\
\hline & & $(0.588)$ & $(0.568)$ & $(0.565)$ \\
\hline \multirow[t]{2}{*}{ Estimated Age $<30$ (I) } & & -0.605 & 0.121 & -0.067 \\
\hline & & $(1.260)$ & $(1.268)$ & $(1.301)$ \\
\hline \multirow[t]{2}{*}{ Estimated Age $>60(\mathrm{I})$} & & -0.834 & $-1.108^{* *}$ & $-1.198^{* *}$ \\
\hline & & $(0.556)$ & $(0.558)$ & $(0.550)$ \\
\hline \multirow[t]{2}{*}{ Previous Donor (I) } & & & $5.650^{* * *}$ & $5.285^{* * *}$ \\
\hline & & & $(1.075)$ & $(1.082)$ \\
\hline \multirow[t]{2}{*}{ Home Value (hundred thousands) } & & & & $0.577^{* * *}$ \\
\hline & & & & $(0.202)$ \\
\hline \multirow[t]{2}{*}{ Constant } & $4.345^{* * *}$ & $4.242^{* * *}$ & $3.273^{* * *}$ & $1.9828^{* * *}$ \\
\hline & $(0.425)$ & $(0.562)$ & $(0.507)$ & $(0.658)$ \\
\hline Observations & 849 & 849 & 849 & 849 \\
\hline$R^{2}$ & 0.022 & 0.025 & 0.096 & 0.108 \\
\hline
\end{tabular}

Note: Dependent variable is donation, including zeros; OLS with robust (standard errors); ${ }^{*} \mathrm{p}<0.10,{ }^{* *} \mathrm{p}<0.05,{ }^{* * *} \mathrm{p}<0.01$.

Table 5: Examining combined effects on donations.

\section{Discussion}

This is the first study to use a field experiment to assess the effectiveness of different raffle designs, a question with substantial implications for fundraisers. Although the standard linear raffle is ubiquitous, quantity discounts are not uncommon, so it is important to know whether altering the mechanism to make it more efficient is attractive to high-value participants. In addition, while we are sure that few people have participated in raffles with explicit quantity penalties, the power of the experimental method 
is that it allows us to test whether other motivations influence mechanism performance.

Our results would seem to be mixed news for fundraisers. The bad news is that the most commonly used mechanism, the standard linear raffle, is unlikely to maximize revenue, but the good news is that there appear to be (at least) two paths to enhanced raffle performance. One recommendation, epitomized by the convex raffle, advises charities to make the mechanism more efficient (and, hence closer to an all-pay auction) so that participants will be incentivized to donate more. We see this clearly in our field data. Conditional on participating, donors give a third more in the efficient format and this benefit comes without the predicted loss of participation. The second prescription advocates ways to emphasize the fairness of the raffle, the simplest of which is to create a raffle in which everyone has exactly the same chance of winning as in our pay what you want raffle. In this case, more people participate because it truly is the case that "anyone can win." As posited, we find that in the field participation does increase substantially (by 14\%), but we also find that the framing of a "fair" raffle matters tremendously because our simple quantity penalty (the concave raffle) does poorly, mostly because participants failed to find it as intuitive as the PWYW. Upon reflection, what is interesting is that a mechanism like the PWYW is more common that one might think. In many membership and donation drives by public radio and television, prizes are awarded randomly among participants, regardless of donation.

This leaves the more fundamental question of whether the strategic incentives surrounding a prize crowd in or crowd out voluntary contributions. Recall that one of the interesting features of the PWYW raffle is that any donation above the $\$ 5$ minimum must be voluntary because it has no impact on one's chances of winning. Consequently, if people give less in the PWYW than in the other formats, it must be the case that the incentive to increase your chances of winning the prize crowds in donations. If, on the other hand, donations are greater in the PWYW, these strategic incentives must crowd out donations. Considering only donations greater than the $\$ 5$ minimum, we find that mean voluntary giving in the PWYW is $\$ 18.97$, it is $\$ 17.17$ in the convex raffle, $\$ 15.00$ in the linear raffle, and $\$ 12.14$ in the concave raffle. Given donations are lower with incentives than without, it appears that there is some evidence of altruism being crowded out; however, only the difference with the concave raffle (the format that seemed least natural to participants) is significant. The lesson learned seems to be that being clever about the incentives of fundraising institutions matters a lot but being straightforward and intuitive appears to matter too. 


\section{References}

Angrist, Joshua and Jorn-Steffen Pischke. 2009. Mostly Harmless Econometrics. Princeton and Oxford: Princeton University Press.

Baker, Leonard. 1958. "Should We Have a National Lottery?" Challenge, 6, 13-17.

Bowles, Samuel and Andra Polania-Reyes. 2012. "Economic Incentives and Social Preferences: Substitutes or Complements?" Journal of Economic Literature, 50(2), 368-425.

Carpenter, Jeffrey; Jessica Holmes and Peter Matthews. 2008. "Charity Auctions: A Field Experiment." The Economic Journal, 118(1), 92-113.

Clotfelter, Charles and Philip Cook. 1990. "On the Economics of State Lotteries." Journal of Economic Perspectives, 4, 105-19.

Corcoran, William. 1984. "Long-run Equilibrium and Total Expenditures on Rentseeking." Public Choice, 43, 89-94.

Dale, Donald. 2004. "Charitable Lottery Structure and Fund Raising: Theory and Evidence." Experimental Economics, 7, 217-234.

DellaVigna, Stefano; List, John; Malmendier, Ulrike. 2012. "Testing for Altruism and Social Pressure in Charitable Giving." Quarterly Journal of Economics, 127(1): $1-56$.

Duncan, Brian. 2002. "Pumpkin Pies and Public Goods: The Raffle Fundraising Strategy." Public Choice, 111, 49-71.

Giving-USA. 2010. "Giving USA, the Annual Report on Philanthropy," AAFRC Trust for Philanthropy.

Landry, Craig; Andreas Lange; John List; Michael Price and Nicholas Rupp. 2006. "Toward an Understanding of the Economics of Charity: Evidence from a Field Experiment." Quarterly Journal of Economics, 121(2), 747-82.

Landry, Craig; Andreas Lange; John List; Michael Price and Nicholas Rupp. 2010. "Is a Donor in Hand Better Than Two in the Bush? Evidence from a Natural Field Experiment." American Economic Review, 100(3), 958-983.

List, John. 2008. "Introduction to Field Experiments in Economics with Applications to the Economics of Charity." Experimental Economics, 11(3), 203-12.

Mason, Dyana. 2013. "Putting Charity to the Test: A Case for Field Experiments

on Giving Time and Money in the Nonprofit Sector." Nonprofit and Voluntary Sector Quarterly, 42(1), 193-202. 
Morgan, John. 2000. "Financing Public Goods by Means of Lotteries." Review of Economic Studies, 67, 761-784.

Morgan, John; Orzen, Henrik and Martin Sefton. 2012. "Endogenous Entry in Contests." Economic Theory, 51, 435-463.

Onderstal, Sander; Schram, Arthur and Adriaan Soetevent. 2013. "Bidding to Give in the Field." Journal of Public Economics, 105, 72-85.

Sweeney, Martin. 2009. The Lottery Wars: Long Odds, Fast Money and the Battle over an American Institution. New York: Bloomsbury.

Tullock, Gordon. 1980. Efficient Rent-seeking. in J. Buchanan, R. Tollison and G. Tullock (eds.), Toward a Theory of Rent-seeking Society, 97-112. College Station: Texas A\&M University Press. 


\section{Appendix - Raffle solicitor scripts}

\section{(Note: organization names have been redacted)}

Hi, our names are and and we're raising money for XYZ. XYZ is an organization in Addison County dedicated to giving access to the tools and resources necessary to meet the community's basic needs. This past year, XYZ provided relief to homes that were being hit by the harsh winter. This has depleted its heating and food assistance budgets, and they need your support.

To raise money, we are conducting a charity raffle. All proceeds of this raffle will benefit XYZ.

This raffle has the prize of a $\$ 500$ gift certificate redeemable at local restaurants. These restaurants are The ABC Café, The DEF Bistro, The GHI, The JKL and The MNO. We will draw the winning ticket during the first week of May and notify the winner.

(Show Pricing Scheme Laminate)

[LINEAR] In this raffle, you will receive 5 tickets for a donation of $\$ 5,10$ tickets for $\$ 10,20$ tickets for $\$ 20$ and so forth. Here are the different contributions you can make and the corresponding number of tickets you will receive. The cost of each ticket is the same regardless of how many tickets you buy. We expect 100 people to participate in the raffle.

[CONVEX] In this raffle, you will receive 5 tickets for a donation of $\$ 5,13$ tickets for $\$ 10,30$ tickets for $\$ 20$ and so forth. Here are the different contributions you can make and the corresponding number of tickets you will receive. The cost of each ticket decreases as you buy more tickets. We expect 100 people to participate in the raffle.

[CONCAVE] In this raffle, you will receive 5 tickets for a donation of $\$ 5,9$ tickets for $\$ 10,15$ tickets for $\$ 20$ and so forth. Here are the different contributions you can make and the corresponding number of tickets you will receive. The cost of each ticket increases as you buy more tickets. We expect 100 people to participate in the raffle.

$[\mathrm{PWYW}]$ In this raffle, you will receive 5 tickets for any donation of $\$ 5$ or more. We would like you to donate whatever you want, 5, 10, 20, 40, or 60 dollars, for the 5 tickets. We expect 100 people to participate in the raffle.

Any questions? Would you like to make a donation to XYZ and enter the raffle? 


\section{Appendix - Robustness (solicitor team fixed effects)}

\begin{tabular}{lcccc}
\hline & $(1)$ & $(2)$ & $(3)$ & $(4)$ \\
\hline Convex - Qty. Discount (I) & 0.047 & 0.050 & 0.050 & 0.052 \\
& $(0.046)$ & $(0.046)$ & $(0.045)$ & $(0.045)$ \\
Concave - Qty. Penalty (I) & -0.012 & -0.011 & -0.011 & -0.010 \\
& $(0.046)$ & $(0.047)$ & $(0.046)$ & $(0.046)$ \\
Pay What You Want (I) & $0.128^{* *}$ & $0.128^{* *}$ & $0.128^{* *}$ & $0.129^{* *}$ \\
& $(0.051)$ & $(0.051)$ & $(0.051)$ & $(0.051)$ \\
Female (I) & & $0.065^{*}$ & $0.066^{*}$ & $0.064^{*}$ \\
& & $(0.035)$ & $(0.034)$ & $(0.034)$ \\
Estimated Age $<30$ (I) & & -0.030 & 0.000 & -0.010 \\
Estimated Age $>60$ (I) & & $(0.079)$ & $(0.081)$ & $(0.082)$ \\
& & $-0.069^{*}$ & $-0.075^{*}$ & $-0.074^{*}$ \\
Previous Donor (I) & & $(0.040)$ & $(0.040)$ & $(0.039)$ \\
& & & $0.196^{* * *}$ & $0.182^{* * *}$ \\
Home Value (hundred thousands) & & & $(0.043)$ & $(0.044)$ \\
& & & & $0.031^{* *}$ \\
Constant & & & & $(0.016)$ \\
& 0.045 & 0.052 & 0.073 & 0.080 \\
\hline
\end{tabular}

Note: Dependent variable is whether one donates or not; linear probability with robust (standard errors); solicitor team fixed effects included; ${ }^{*} \mathrm{p}<0.10,{ }^{* *} \mathrm{p}<0.05,{ }^{* * *} \mathrm{p}<0.01$.

Table A1: Fixed effect models of the extensive margin. 


\begin{tabular}{|c|c|c|c|c|}
\hline & $(1)$ & $(2)$ & (3) & $(4)$ \\
\hline \multirow[t]{2}{*}{ Convex - Qty. Discount (I) } & $2.808^{* * *}$ & $2.792^{* *}$ & $2.541^{* *}$ & $2.542^{* *}$ \\
\hline & $(1.098)$ & $(1.099)$ & $(1.055)$ & $(1.041)$ \\
\hline \multirow[t]{2}{*}{ Concave - Qty. Penalty (I) } & -1.177 & -1.157 & $-1.265^{*}$ & $-1.303^{*}$ \\
\hline & $(0.787)$ & $(0.802)$ & $(0.770)$ & $(0.768)$ \\
\hline \multirow[t]{2}{*}{ Pay What You Want (I) } & 1.056 & 1.066 & 1.305 & 1.399 \\
\hline & $(1.323)$ & $(1.320)$ & $(1.313)$ & $(1.310)$ \\
\hline \multirow[t]{2}{*}{ Female (I) } & & -0.354 & -0.149 & -0.384 \\
\hline & & $(1.057)$ & $(1.001)$ & $(1.000)$ \\
\hline \multirow[t]{2}{*}{ Estimated Age $<30$ (I) } & & 0.022 & 1.409 & 1.555 \\
\hline & & $(2.146)$ & $(2.103)$ & $(2.147)$ \\
\hline \multirow[t]{2}{*}{ Estimated Age > 60 (I) } & & -0.545 & -0.533 & -0.703 \\
\hline & & $(0.894)$ & $(0.863)$ & $(0.853)$ \\
\hline \multirow[t]{2}{*}{ Previous Donor (I) } & & & $5.502^{* * *}$ & $5.293^{* * *}$ \\
\hline & & & $(1.375)$ & $(1.344)$ \\
\hline \multirow[t]{2}{*}{ Home Value (hundred thousands) } & & & & $1.037^{* * *}$ \\
\hline & & & & $(0.366)$ \\
\hline \multirow[t]{2}{*}{ Constant } & $9.753^{* * *}$ & $10.103^{* * *}$ & $8.910^{* * *}$ & $6.930^{* * *}$ \\
\hline & $(2.078)$ & (1.978) & $(1.897)$ & $(2.017)$ \\
\hline Observations & 434 & 434 & 434 & 434 \\
\hline$R^{2}$ & 0.046 & 0.047 & 0.112 & 0.131 \\
\hline
\end{tabular}

Note: Dependent variable is donation, conditional on being positive; OLS with robust (standard errors); solicitor team fixed effects included. ${ }^{*} \mathrm{p}<0.10,{ }^{* *} \mathrm{p}<0.05,{ }^{* * *} \mathrm{p}<0.01$.

Table A2: Fixed effect models of the intensive margin. 


\begin{tabular}{|c|c|c|c|c|}
\hline & (1) & $(2)$ & (3) & (4) \\
\hline \multirow[t]{2}{*}{ Convex - Qty. Discount (I) } & $1.927^{* * *}$ & $1.949 * * *$ & $1.949^{* * *}$ & $1.985^{* * *}$ \\
\hline & $(0.732)$ & $(0.732)$ & $(0.698)$ & $(0.694)$ \\
\hline \multirow[t]{2}{*}{ Concave - Qty. Penalty (I) } & -0.658 & -0.639 & -0.629 & -0.616 \\
\hline & $(0.534)$ & $(0.538)$ & $(0.522)$ & $(0.519)$ \\
\hline \multirow[t]{2}{*}{ Pay What You Want (I) } & $1.847^{* *}$ & $1.851^{* *}$ & $1.863^{* *}$ & $1.870^{* *}$ \\
\hline & $(0.924)$ & $(0.934)$ & $(0.925)$ & $(0.924)$ \\
\hline \multirow[t]{2}{*}{ Female (I) } & & 0.467 & 0.496 & 0.461 \\
\hline & & $(0.603)$ & $(0.581)$ & $(0.579)$ \\
\hline \multirow[t]{2}{*}{ Estimated Age $<30$ (I) } & & -0.379 & 0.472 & 0.278 \\
\hline & & $(1.340)$ & $(1.332)$ & $(1.363)$ \\
\hline \multirow[t]{2}{*}{ Estimated Age $>60(\mathrm{I})$} & & $-0.933^{*}$ & $-1.087^{*}$ & $-1.082^{*}$ \\
\hline & & $(0.564)$ & $(0.559)$ & $(0.551)$ \\
\hline \multirow[t]{2}{*}{ Previous Donor (I) } & & & $5.545^{* * *}$ & $5.276^{* * *}$ \\
\hline & & & $(1.069)$ & $(1.068)$ \\
\hline \multirow[t]{2}{*}{ Home Value (hundred thousands) } & & & & $0.607^{* *}$ \\
\hline & & & & $(0.238)$ \\
\hline \multirow[t]{2}{*}{ Constant } & $2.836^{* * *}$ & $2.884^{* * *}$ & $2.314^{* *}$ & 1.211 \\
\hline & $(1.027)$ & $(0.977)$ & $(0.956)$ & $(1.040)$ \\
\hline Observations & 849 & 849 & 849 & 849 \\
\hline$R^{2}$ & 0.047 & 0.050 & 0.116 & 0.126 \\
\hline
\end{tabular}

Note: Dependent variable is donation, including zeros; OLS with robust (standard errors); solicitor team fixed effects included. ${ }^{*} \mathrm{p}<0.10,{ }^{* *} \mathrm{p}<0.05,{ }^{* * *} \mathrm{p}<0.01$.

Table A3: Fixed effect models of donations (including zeros). 